
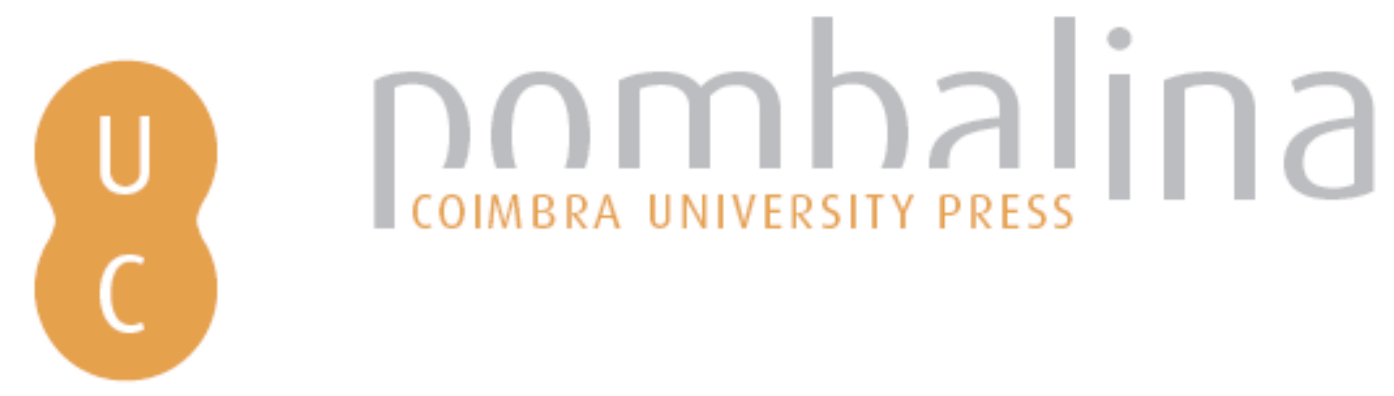

Os Lusíadas: focagens e desfocagens (a propósito da leitura do poema, segundo os programas oficiais)
Autor(es):
Sequeira, Maria do Carmo Castelo Branco de
Publicado por: Imprensa da Universidade de Coimbra
URL
persistente:
URI:http://hdl.handle.net/10316.2/31271
DOI:
DOI:http://dx.doi.org/10.14195/978-989-26-0569-2_48
Accessed : $\quad$ 26-Apr-2023 11:29:52

A navegação consulta e descarregamento dos títulos inseridos nas Bibliotecas Digitais UC Digitalis, UC Pombalina e UC Impactum, pressupõem a aceitação plena e sem reservas dos Termos e Condições de Uso destas Bibliotecas Digitais, disponíveis em https://digitalis.uc.pt/pt-pt/termos.

Conforme exposto nos referidos Termos e Condições de Uso, o descarregamento de títulos de acesso restrito requer uma licença válida de autorização devendo o utilizador aceder ao(s) documento(s) a partir de um endereço de IP da instituição detentora da supramencionada licença.

Ao utilizador é apenas permitido o descarregamento para uso pessoal, pelo que o emprego do(s) título(s) descarregado(s) para outro fim, designadamente comercial, carece de autorização do respetivo autor ou editor da obra.

Na medida em que todas as obras da UC Digitalis se encontram protegidas pelo Código do Direito de Autor e Direitos Conexos e demais legislação aplicável, toda a cópia, parcial ou total, deste documento, nos casos em que é legalmente admitida, deverá conter ou fazer-se acompanhar por este aviso.

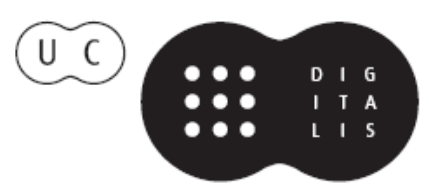




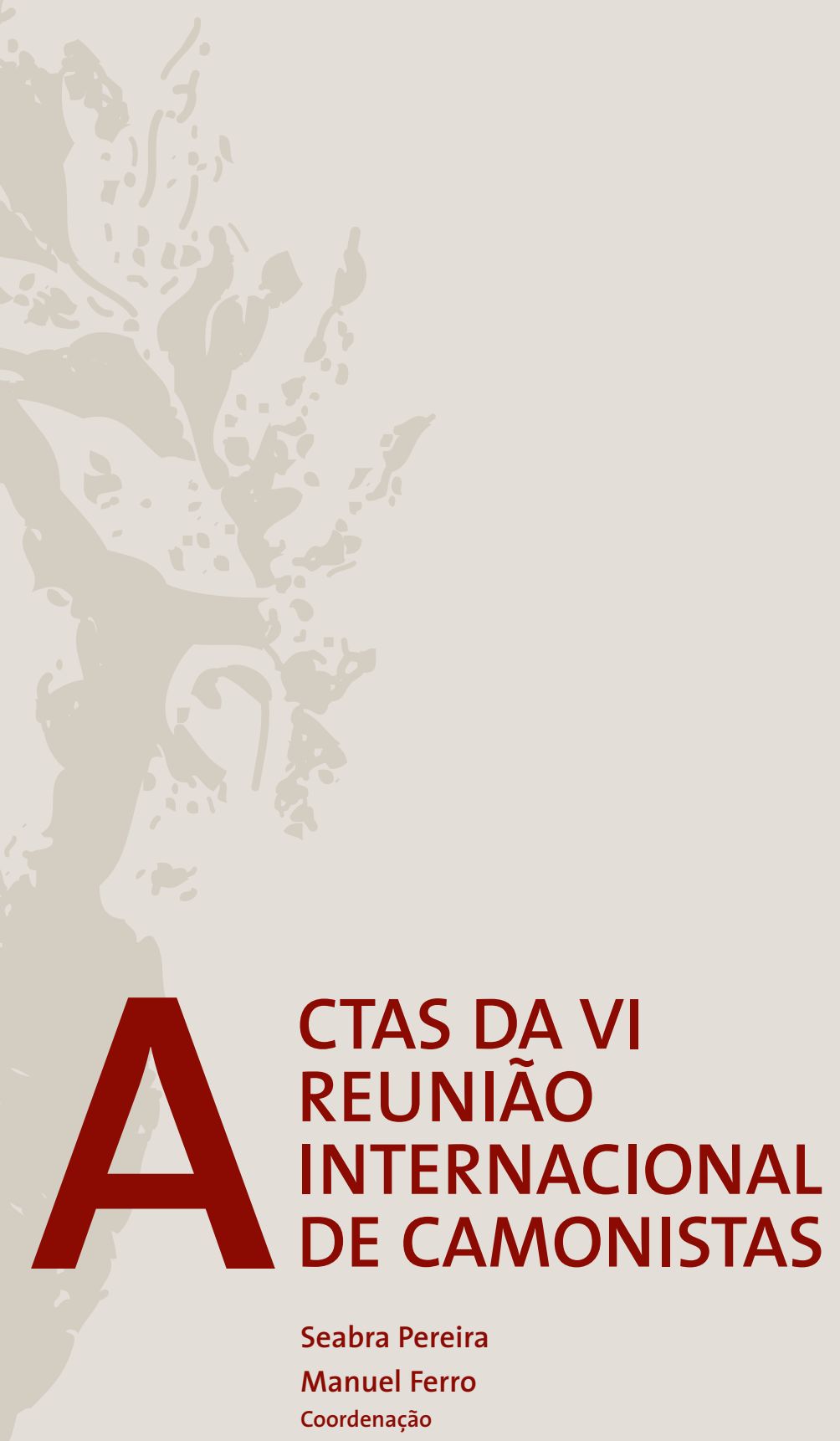


Maria do Carmo Castelo Branco de Sequeira

Instituto Politécnico do Porto

\section{OS LUSÍADAS: FOCAGENS E DESFOCAGENS \\ (A propósito da Leitura do Poema, segundo os programas oficiais)}

Numa crónica bem recente (3/4/96), inserida no "Caderno Leituras" do Público e triplamente titulada de Mistério decifrado / Leitor e Público / Circunspecção, Mário de Carvalho, um pouco envergonhado por ainda ser capaz de folhear Chateaubriand, mas feliz por, finalmente, ter descoberto, pelas máos do tradutor Camilo, o sentido da estranha palavra frankisk que, desde a primeira leitura do Eurico «lhe moera a curiosidade» e, simultaneamente encantado (presume-se) por encontrar um motivo para o seu artigo, afirma a certa altura:

"Toda a minha vida fui confrontado com textos que não percebia, ou que não podia perceber em parte. A poesia trovadoresca, Camóes, Samuel Usque, o cultismo e o conceptismo, faziam parte do programa dos liceus. Não eram textos fáceis. Não bastava, sequer, "tirar" o vocabulário. Era necessário, mesmo numa aproximação epidérmica, que se procedesse a uma análise do contexto, que se manejassem conhecimentos históricos, ou se cruzassem referências literárias. Esse esforço - algo sofredor - foi-nos exigido e ainda bem.

Como se havia de fazer para facultar os textos à nossa incipiência? Actualizar a ortografia arcaica (aliás preciosa para a compreensáo sumária de alguma etimologia)? Alterar os conteúdos, apresentando realidades facilmente reconhecíveis, com o trovador a andar de porsche e o jogral de bicicleta? Verter Os Lusíadas em prosa, de maneira a propiciar uma leitura seguida e airada, com dispensa da divisão das oraçóes? Seccionar os longuíssimos períodos de Samuel Usque, violando-lhe os ritmos, para uma leitura menos cansativa? Em suma, falsificar os textos?”

De forma levemente humorística, mas com grande oportunidade, Mário de Carvalho vem colocar um problema pedagogicamente relevante: sob o pretexto de "motivar», "atrair os alunos para a leitura», no fundo, facilitar até ao absurdo, deve o professor traduzir, adulterar, transformar o referido frankisk em "acha de dois gumes»?

Leitores incipientes, os alunos do $9^{\circ}$ ano do Ensino Básico começam a contactar com Os Lusiadas. E logo os Programas Oficiais traçam uma linha de referência sobre a qual os professores devem traçar as suas planificaçóes operativas. Essa linha, mesmo entendida com toda a abertura, é uma dupla ordem (no sentido de "disposição regular 
e metódica" e de "força disciplinar") e nessa dupla ordem está o primeiro e incoerente fraccionamento, a saber:

"De Os Lusíadas, de Luís de Camóes, deverá fazer-se leitura orientada das seguintes estrofes" (devidamente apontadas) correspondentes a «Proposiçáo, Viagem para a Índia, História de Portugal e Mitologia pagã».

Nas indicaçóes sobre leitura orientada, os autores do Programa têm, é certo, o cuidado de avisar de que "em todas as actividades» deve preservar-se "o sentido global das obras». Mas será que esse aviso serve num momento em que o próprio discurso aponta já para uma selecção restritiva?

Se a análise da "Proposição" é naturalmente pacífica e desejável para o entendimento do texto, a formulação e selecção dos outros aspectos é questionável a vários níveis.

Será, por exemplo, que a viagem para a Índia não constitui um aspecto da História de Portugal? Por detrás dessa aparente organização / desorganização das secçôes requeridas (motivadas, quanto a nós, por uma apressada leitura do Luís de Camóes de António José Saraiva, onde ele, de facto fala em "diferentes planos», mas entendidos como formas descontínuas do "desenvolvimento da matéria» que terão na mitologia a força unificadora) não deveria estar antes uma divisão dos discursos - aquela intricada rama de discursos encaixados, onde "as histórias se inserem como assuntos» - como refere Jacinto do Prado Coelho (1976: 89-90)?:

"Encarando Os Lusíadas à luz destes conceitos (os conceitos de "sistema da história" e "sistema do discurso" de Benveniste e de "mundo narrado" e "mundo comentado" de Weinrich), verificamos, antes de mais, que o poema constitui, do princípio ao fim, um discurso (épico, naturalmente) em que a História ou as histórias se inserem como assuntos; discurso de acordo com a definição de Benveniste: um indivíduo, o autor, cuja presença se manifesta frequentemente, dirige-se a outro, D. Sebastiáo, para nele exercer influência. O autor oferecelhe como espectáculo digno de meditaçáo o povo português e os seus feitos (...). Mas o discurso primeiro, que é o do autor endereçado ao Rei e ao povo, contém discursos secundários que por sua vez podem integrar discursos menores. Precisando, às personagens da narrativa de $\left(\mathrm{d}_{1}\right)$ dá o autor a palavra, geralmente em discurso directo $\left(\mathrm{dd}_{2}\right)$, e estes discursos das personagens encerram acçóes com outras personagens que "ouvimos" falar também..."

E mesmo aceitando aqueles planos de que fala o Programa, porque se reduzirá a História de Portugal a dois episódios (o de "Inês de Castro" e o da "Batalha de Aljubarrota”)? Será para contrapor à guerra política o drama amoroso, já que, como afirma Maria Leonor de Sousa, "na tradiçáo portuguesa, Pedro e Inês distanciaram-se das realidades do pais medieval em que viveram; tornaram-se 'um dos simbolos em que a alma de Portugal se reconhecia', transcenderam os limites do real, encarnando o mito do amor para além da morte.» (1984: 16-17)? E por que considerar então a chamada História de Portugal como um factor de representação, aparentemente isolado dentro do poema, sabendo, como sabemos, que, no texto literário, a inserção dos factos 
históricos sofre a influência das leis da ficcionalidade que transformam a referência em poesia, e alteram portanto toda a possível "verdade" factual?

E que dizer do último aspecto (Mitologia pagã)?

O programa fala unicamente e, paradoxalmente, como uma espécie de fecho ornamental, no Concílio dos deuses no Olimpo. Naturalmente que o bom senso do professor, ao longo da análise desse excerto não deixará de chamar a atenção para a importância (perfeitamente delineada nesse concílio) da mitologia, enquanto suporte daquela unidade accional de que falava António José Saraiva (na obra anteriormente citada) e encontrará meios operatórios de fazer com que o aluno descubra todos os passos da intriga dos deuses que irão condicionar o desenvolvimento da viagem. Mas o Programa deveria talvez evidenciar melhor os meios de encontrar a sua recontextualização, de forma a que a coerência nunca pudesse ser perdida.

De facto, a leitura de excertos pode ser motivadora e dinâmica se suportar em si o objectivo de uma percepção de todo, isto é, se conduzir a um levantamento de signos que possam servir de hipótese para uma pré-construção textual permitindo que o aluno levante os sinais daquilo a que poderíamos chamar, com Roland Barthes, de "código hermenêutico" $(S / Z)$, ou, para nos servirmos da expressão de Umberto Eco, convide o aluno a "passeios inferenciais", onde a sua "enciclopédia" sirva de indicador global; mas essa mesma leitura poderá ser altamente nefasta se retirar do texto a "actividade mimética", o "processo dinâmico de representação” - expressóes sob as quais Paul Ricoeur traduz a fórmula aristotélica de mimesis praxeos.

$\mathrm{Na}$ verdade, como também diz Emília Amor, "... a utilização de fragmentos descontextualizados - os excertos - resultantes de cortes e de manipulaçôes são, quase sempre, perturbadoras de um entendimento mais completo dos textos e, quase sempre, desrespeitadores das obras originais, na sua integridade e sentido pleno.» (1993: p. 98).

Consubstanciando-se o Ensino Básico no quadro de uma formação universal e homogénea e sabendo-se que, para muitos alunos, constitui toda a formação escolar a partir da qual entram no mundo do trabalho, o conhecimento de obras, como $O s$ Lusíadas, deveria corresponder a uma certa sistematização, a uma configuração básica, que abrisse caminho a novas aventuras de leitura pessoal, ou, no caso da continuidade dos estudos, servisse de grande plano para as novas leituras do Poema que os Programas do Ensino Secundário propóem.

De facto, o ensino/aprendizagem d'Os Lusíadas continua, estendendo-se (no caso do Programa A - o único que iremos considerar) pelos três anos que constituem, dentro dos actuais quadros curriculares, o Ensino Secundário.

Aparentemente de uma forma totalmente libertadora (ou libertina?) o mesmo indicador se repete ao longo dos três anos, em posiçáo final no quadro de distribuiçáo das Leituras do texto narrativo (nos $10^{\circ}$ e $11^{\circ}$ anos) ou em posição inicial (no $12^{\circ}$ ). É o seguinte:

"Camóes - Os Lusíadas (excertos)".

No entanto, de uma forma talvez mais perigosa ainda do que acontecera no $9^{\circ}$ ano, há fortes determinantes das opçôes dos professores no âmbito das suas programaçôes individuais ou colectivas. Na verdade, essa distribuição das Leituras é antecedida por novas imposiçóes que passo a citar: 
"As obras nacionais indicadas para leitura obrigatória - a conjugar com outras de proveniência estrangeira - hão-de, em simultâneo, salvaguardar o tratamento das temáticas e perspectivação do panorama diacrónico e sincrónico da literatura portuguesa. Por isso, o aluno disporá sempre dos textos indispensáveis ao estabelecimento da situaçáo das obras num período, corrente, escola ou fase particular da evolução do autor. E nesse mesmo sentido se há-de entender que a leitura de textos de Gil Vicente e de Camóes, distribuída ao longo dos três anos do ciclo, seja feita de acordo com a oportunidade das temáticas propostas." (p. 36) (o negrito é nosso)

Assim, "o professor obediente" deverá respeitar as "Temáticas organizadoras das Leituras", a saber:

- para todos os três anos, "a expressão dos sentimentos" e a relação com a realidade exterior";

- para os $11^{\circ}$ e $12^{\circ}$, "a intervenção na vida social" e "a expressão comprometida";

- e, só para o $12^{\circ}$, "a reflexão sobre a condição humana” e "a reflexão sobre o mundo".

Para além dos problemas que poderiam levantar-se sobre a formulação destes pressupostos temáticos e mesmo que aceitássemos tal formulação, estabelecer o movimento da leitura de fora para dentro do texto parece-nos um movimento inverso e constrangedor. Se nos valores exógenos se poderão encontrar focos ideológicos e reflexos de problemáticas histórico-sociais (para além doutras de natureza literária, como ligaçóes arquitextuais, intertextuais ou periodológicas), é na obra que elas deverão ser levantadas e não "ajustar" a obra e essas pretensas temáticas.

A compreensão de uma "história" implica a construção de um mundo. Reparti-lo, para responder a temáticas externas (configuradoras, neste caso, do percurso de um ou mais anos lectivos), é quebrar esse "mundo", distorcendo-o de forma arbitrária e perigosa.

Naturalmente que todas estas preocupaçóes estiveram na mente do grupo de professores que, recentemente, levou a cabo um "ajustamento" dos Programas do Ensino Secundário, possivelmente para entrar em vigor em 1997/98, e onde (entre outros aspectos) se procurou "uma reformulação dos critérios de selecção das leituras metódicas (obrigatórias)», agora apoiada, numa metodologia de ensino "sistemático e diacrónico da história literária, numa perspectiva aberta e criativa», acautelando embora a não "reabilitação do ensino tradicional e excessivamente dirigido da História da Literatura».

Dentro desta perspectiva, o ensino d'Os Lusíadas passou a fixar-se no $10^{\circ}$ ano e dentro de uma visão globalizante e classicamente enquadrada:

«Os Lusíadas (visão global da obra; leitura de fragmentos ilustrativos da estrutura narrativa e conceptual da epopeia)» (p. 33).

Apesar da redução espacial e temporal, o professor poderá seguir, em linhas gerais, e com a liberdade que "os limites da interpretaçáo" impóem, o trajecto definido por Carlos Reis (1990: 147-148) para a leitura integral da obra narrativa, isto é, por um lado, tendo em conta a sua contextualização e, por outro, a sistematização categorial da leitura, quer no âmbito da estrutura da história (a análise da Personagem, da Acção e do Espaço), quer no âmbito do discurso e sua enunciaçáo (a análise do Tempo, do Modo e da Voz). 
No caso específico d'Os Lusíadas, várias são as perspectivas levantadas pelos autores que poderão servir de base para leituras didácticas globalizantes. Permito-me referir, essencialmente, duas, que terei de simplificar até aos limites de dois simples roteiros didácticos:

1. Um plano de leitura partindo do desenvolvimento do tópico do encarecimento apresentado por Jacinto Prado Coelho (1976), que permita, num primeiro momento, contextualizar a obra, integrando-a numa estética "do veraz e do conciso" própria de um determinado momento temporal.

Como afirma o autor: "podemos considerá-la como expressão dum momento cultural em que o Homem já não se sente mero joguete das forças naturais, antes ganhou consciência de que, observando-as, e mercê também de tenacidade e ousadia, é capaz de as dominar $e$ dirigir» (p. 88).

E, num segundo momento, que permita igualmente uma sistematizaçáo da leitura, através da análise dos diferentes discursos e das vozes que os enunciam;

2. Um plano de leitura que, partindo do tópico da viagem simbólica - base da interessante leitura d'Os Lusíadas por Helder Macedo (1980: 33-59) -, constitua o motivo para um trajecto didáctico, em que seja possível estabelecer a caminhada do herói, através da combinação de vários tempos: o tempo da narraçáo, e, mesmo, cruzando a História e a Literatura, o tempo de Fernando Pessoa e d'A Mensagem.

Concluindo, e retomando os títulos da pequena crónica de Mário de Carvalho: todo o projecto de ensino da Literatura assenta, não no objectivo de decifrar o mistério (tarefa impossível, onde, para nossa alegria, podem surgir só pequeninas decifraçóes contextualizadas ao longo da vida), mas, pelo contrário, em fazer com que os alunos sintam que a obra literária é um mistério sim, mas sem possibilidade de total e definitiva decifração. Citando Umberto Eco (1995: 12) que, por sua vez, cita Jorge Luís Borges, "um bosque é um jardim com veredas que se bifurcam. Mesmo quando num bosque não há veredas, cada qual pode traçar o seu próprio percurso e decidir ir para a esquerda ou para a direita de uma certa árvore e fazer uma escolha a cada árvore que se lhe depare».

Mas terá de o fazer com Circunspecção, isto é, não se esquecendo que todos nós, leitores empíricos, somos simples homens, marcados pela nossa historicidade, e, por isso, tendo de caminhar com ponderação e olhando sempre à nossa volta.

Como afirma Aguiar e Silva (1987:22) e para terminar:

“... a palavra de Deus só pode subtrair-se às mutaçóes e às rupturas interpretativas se for em absoluto descontextualizada, isto é, se for unívoca, universal e intemporalmente interpretada por uma autoridade inalterável que se examine à finitude da consciência e da razão históricas.

Os homens, porém, mesmo os filólogos mais eruditos, de mais alto rigor exegético e de mais acurada acribia, não lêem assim..."

E ainda bem. Porque se assim não fora, não estaríamos aqui reunidos, reflectindo ainda sobre "o mistério" da obra de Camóes e sobre os problemas que continua a levantar a sua leitura. 